\title{
ATUAÇÃO DO ENFERMEIRO NA EQUIPE MULTIPROFISSIONAL *
}

\author{
Maria José Chaves Costa **
}

\begin{tabular}{ll} 
& RBEn/06 \\
\hline
\end{tabular}

COSTA, M.J.C. - Atuaçāo do enfermeiro na equipe multiprofissional. Rev. Bras. Enf.; DF, 31 : 321-339, 1978.

\section{1 - INTRODUÇAO}

O hospital na época atual, com o avanço tecnológico e cientifico, sofre as contingências de grupos sociais, não podendo dissociar-se do desenvolvimento que vem ocorrendo em outros setores. Ele precisa ser a expressão quantitativa e qualitativa da assistência ao paciente. Os objetivos que norteiam a instituição hospitalar são alcançados através da equipe multiprofissional onde cada elemento é uma peça de engajamento de toda uma engrenagem 12.

O desenvolvimento do trabalho em equipe obedece a dinâmica uniforme $e$ coerente de um plano bem estudado e não simplesmente o resultado da composição de diversos profissionais interdisciplinares para prestarem uma assistência eficiente e condigna ao paciente.

Num trabalho isolado, é comum que a eficiência dos profissionais seja com- prometida por um falho desempenho de um dos atuantes, recaindo as conseqüuências sobre o paciente. Quando as açōes são integradas, as realizaçōes se multiplicam e os perigos são reduzidos. Se a cura do enfermo depende não só do esforço de um e sim de vários profissionais, por que então trabalhar isolado? Por que não unir todas as forças e potencialidades em grupo que visa atingir o mesmo fim que é a assistência ao paciente 5?

"O Enfermeiro é um dos elementos que compōe a equipe multiprofissional no sistema de saúde: colabora no planejamento e execução dos programas a serem desenvolvidos e pela intimidade com os problemas, é o elemento credenciado para identficar as necessidades do paciente, sendo o contingente humano de malor sensibilidade na promoção de saúde do indivíduo e da coletividade 12".

* Trabalho apresentado na VII Jornada Maranhense de Enfermagem - S. Luís - 1978.

* Prof. Titular do Departamento de Enfermagem da Universidade Federal do Maranhāo e Enfermeira do INAMPS - Hospital Presidente Dutra. 
COSTA, M.J.C. - Atuaçāo do enfermeiro na equipe multiprofissional. Rev. Bras. Enf.; DF, $31: 321-339,1978$.

No presente trabalho objetiva-se destaciar a atuação da equipe multiprofissional junto ao paciente no periodo de huspitalização e o enfermeiro integrandj esta equipe a nível de decisão atraves do Processo de Enfermagem.

\section{2 - EQUIPE MULTIPROFISSIONAL - CONCEITO}

Equipe Multiprofissional é a junção de esforços e interesse de um grupo de profissionais que reconhecem a interdependência com os outros componentes e se identficam com um trabalho de caráter cooperativo e não competitivo, com o fim de alcançar um objetivo comum cuja atividade sincronizada e coordenada caracteriza um grupo estritamente ligado" 512.

O trabalho em equipe não significa portanto, a somação de indivíduos organizados para uma tarefa comum, mas a integração de cada elemento que a compōe, atendendo às peculiaridades grupais, e muma reunião de técnicos em várias especialidades profissionais, desempenhando funçōes harmônicas numa verdadeira intercomplementação 12.

\section{1 - Vantagens do Trabalho em Equipe Multiprofissional}

Da noção de interdependência a influência bilateral da conduta do grupo interprofissional, surgem os resultados esperados de qualquer função em equipe: a idéia do sinergismo 5 .

Sobre o assunto, assim se expressa DE FELICE (1976), "os pacientes consideram a equipe como seu médico". E ciuanto 20 grau de satisfação obtida pelo paciente com relação ao trabalho de equipe, o autor citou SILVER, o qual observou que $94 \%$ dos pacientes expressaram satisfação com a assistência combinada, considerando-a melhor do que recebida por um médico somente e, $90 \%$ dos pacientes consideraram a as- scciação de um médico e um profissioval afim de área de saúde, como uma tendência inevitável na prática da medicina.

Evidenciado está, que o trabalho realizado por equipe multiprofissional constitui importância relevante com as seguintes vantagens:

a) assegura a participação de toda a equipe através de um trabalho integrado;

b) propicia uma assistência mais condigna e humana ao paciente por meio da interação multiprofissional;

c) centra as responsabilidades através do trabalho có-praticado;

d) fortalece as relaçōes entre os profissionais, paciente e família para 0 alcance dos objetivos;

e) aumenta o aproveitamento da capacidade profissional pela coesão do trabalho;

f) favorece o relacionamento interprofissional.

\section{2 - Requisitos para um trabalho em equipe}

Um constante interesse para alcançar os objetivos propostos deve nortear a equipe, onde cada elemento necessita do trabalho do outro através de uma estreita colaboração. E imprescindível que os participantes da equipe apresentem requisitos como sejam:

a) espírito de equipe - é o desejo de unir forças para obtenção do objetivo comum;

b) participação - acreditar e se esforçar para realizar alguma coisa;

c) intercomunicação - ocorre quando há um perfeito conhecimento e segurança no campo específico de ação e, geral nas outras áreas;

d) capacidade de assumir responsabilidade - é aceitação total do trabalho com um esforço contínuo para bem desempenhar as funçōes; 
COSTA, M.J.C. - Atuação do enfermeiro na equipe multiprofissional. Rev. Bras. Enf.; DF, $31: 321-339,1978$.

e) satisfação - é o sentimento de segurança, de amplitude em fazer parte de um trabalho que reflita satisfação intima.

\section{3 - Membros da Equipe Multi- profissional}

A formação da equipe multiprofissioral depende do trabalho a ser executado. No sistema de saúde e na instituição hospitalar, apresenta a seguinte

a) Administrador Hospitalar

b) Médico

c) Enfermeiro

d) Assistência Social

e) Nutricionista

f) Psicólogo

g) Terapeuta

h) Farmacêutico

i) Odontólogo 12 .

Muitos modelos de equipe são sugeridos, havendo um grande debate quanto à sua composição, sendo aconselhável grupos pequenos para evitar insatisfaçñes, divergências, indiferentismo e desintegração, o que possibilita a formação de núcleos.

A OMS apresenta a seguinte composição para o pessoal:

a) Pessoal ideal:

- Médico Sanitarista

- Enfermeiro de Saúde Pública

- Veterinário de Saúde Pública

- Odontólogo de Saúde Pública

- Engenheiro de Saúde Pública

- Inspetor de Saúde Pública

- Fiscal de Saúde Pública

- Visitador Sanitário

- Técnico de Laboratório Clínico, RX, etc.

b) Pessoal Minimo:

- Médico Sanitarista

- Enfermeira de Saúde Pública ou Auxiliar de Enfermagem

- Visitadora Sanitária
- Técnicos de Laboratório Clínico e de RX

- Parteira.

c) Pessoal Possível:

- Médico

- Atendente

- Inspetor de Saneamento

- Escriturário, etc. 4.

Estas equipes são compostas para uma estrutura de organização onde a assisiência é primária, o que vale dizer, funcionam em torno das necessidades da população particular de enfermos e de recursos disponíveis que, antes de qualquer noção do que deva ser a estrutura da equipe ideal de assistência básica 5.

ALVARENGA (1973), prevê grupos pequenos para uma equipe multiprofissional (no máximo 12 elementos), sendo que a liderança deve recair sobre o administrador. Este como líder da equipe terá inúmeras oportunidades de ver $\mathrm{e}$ sentir bem de perto o funcionamento de todos os serviços da instituição e, ainda, por ser a autoridade máxima do hospital, possui potencial técnico e especializado aliado às habilidades específicas de coordenação.

Do resultado de nossa experiência no setor hospitalar, voltado para a assistência ao paciente em regime de internação parece razoável sugerir uma equipe básica com o número de 4 componentes:

a) Médico

b) Enfermeiro

c) Assistente Social

d) Nutricionista.

Os demais profissionais, funcionam à distância complementando a equipe básica, como consultores, à proporção das necessidades do paciente.

Um líder de equipe constitui necessidade imperiosa, podendo recair preferentemente sobre o médico ou enfermeiro, visto que na equioe de saúde 
COSTA, M.J.C. - Atuação do enfermeiro na equipe multiprofissional. Rev. Bras. Enf.; DF, 31 : 321-339, 1978.

hospitalar o líder técnico do sistema é o médico, já a orientação terapêutica inclui também a participação do enfermeiro, pois os cuidados de enfermagem são parte do processo terapêutico ${ }^{6}$.

Em torno do assunto de FELICE (1976), assim se expressa: "Há tantas interdependências no trabalho em equipe, que não basta a simples estrutura hierárquica. Por esta razão, as linhas de autoridade e delegação de responsabilidades estão menos estruturadas, são mais flexiveis e mais ambígüas".

\section{4 - Fatores que impedem o funcio- namento eficaz da equipe multi- profissional}

O trabalho em equipe multiprofissional nem sempre resulta perfeitamente uniforme e sem incidentes. O mesmo não nasce expontaneamente, sendo que uma verdadeira conscientização do papel de cada elemento contribui para eliminar aspectos que interferem em seu funcionamento eficaz. Muitos fatores contribuem para o não cumprimento das verdadeiras funções de equipe:

a) Individualismo - um estudo sobre as atitudes dos médicos com relação ao trabalho em equipe, feito por Kane e Kane 5, resultou na seguinte observação: " $82 \%$ dos médicos pensam que poderiam a.tender adequadamente aos enfermos sem ajuda de outros profissionais sanitários. Admitiram que a tendência do médico a considerar-se a si mesmo em uma posição de autoridade em relação uos seus pacientes, guarda uma relação paralela com sua tendência a descartar a necessidade de experiência dos outros.

FERREIRA SANTOS (1973), cita: "o produto do trabalho, a tarefa principal (cura do doente) é entretanto consideracia do médico". Mesmo quando outros nrofissionais atuam eficientemente, a iradição diz que o trabalho poderia ter sido feito sem esses auxílios".
O MEC (Ministério da Educação e Cultura) 2, propõe diretrizes para eliminar esse individualismo quando assim se expressa: "Considerando a evidência de que, cada vez mais, o médico deve trabalhar em equipe multiprofissional, que sejam realizadas com maior freqüência, as técnicas de trabalho em grupo e proporcionadas experiências, sempre que possível, incluindo alunos de diferentes categorias profissionais".

b) Tradicionalismo - este aspecto refere-se à enfermagem como tradição de caridade, imagem materna, que executa técnicas e cumpre ordens médicas, o que tem dificultado afirmar o alcance, a nível de seus pares universitários, de conhecimento em áreas específicas de enfermagem. Só paulatinamente o enfermeiro está sendo reconhecido como autoridade no seu campo ${ }^{6}$.

c) Autoritarismo - a delimitação do âmbito de poder do médico, enfermeiro e outros profissionais, é um dos pontos críticos no interrelacionamento multiprofissional. A tomada de consciência de que a enfermagem moderna, é científica, e com direito a este reconhecimento, faz com que os enfermeiros se insurjam contra a autoridade que outros profissionais julgam ter sobre os mesmos 6 .

Qutros fatores interferem para inibir o funcionamento da equipe: alto interesse econômico, profissionalismo, diferenças de nível sócio-cultural, valores, atitudes e crenças ${ }^{5}$.

\section{5 - O trabalho de equipe}

O ponto de partida para o trabalho de equipe multiprofissional deve estar centrado numa filosofia em que, o paciente e seus problemas, circunstancialmente, depende de todos, com igual intensidade dentro da área de competência de cada elemento do grupo. 
COSTA, M.J.C. - Atuaçāo do enfermeiro na equipe multiprofissional. Rev. Bras. Enf.; DF, $31: 321-339,1978$.

O paciente ao ser encaminhado para a unidade de internação deve ter sentido a abordagem decorrente do processo médico e de enfermagem, pelo menos, na fase descritiva ou seja:

a) anmnese e diagnóstico médico quando o paciente consulta o médico;

b) histórico de enfermagem e diagnóstico de enfermagem * quando o paciente é recebido pelo enfermeiro.

Nas fases subseqüentes ou seja: de intervenção e avaliação, é necessário que sejam atendidas as diferenciações das necessidades dos pacientes. A partir dessa diversificação de necessidades é que a equipe multiprofissional tornase imprescindível ao integral atendimento do paciente.

\subsection{1 - Roteiro de sistemática opera- cional para o trabalho de equi- pe multiprofissional}

Para assegurar o necessário desenvolvimento do funcionamento da equipe, é fundamental um roteiro para a orientação do trabalho, constando de:

a) Visita diária ao paciente - os membros da equipe determinam um horário para o encontro diário a fím de prucederem em conjunto a visita ao paciente. $O$ prontuário é um elemento utilizado pelo grupo, sendo que a abordagem ao paciente deve ser informal e as queixas, observações e evolução da doença são registradas 'a posteriori”, na folha de evolução clínica.

b) Análise e discussão da evolução do paciente - precede às prescrições, senro uma das fases mais importantes do trabalho, onde os elementos do grupo se interrelacionam para a determinação da assistência nas 24 horas. c) Prescrições - cada membro da equipe, na área de sua competência, efetua a prescrição do tratamento para o paciente. A prescrição é do conhecimento de todos, sendo discutida e analisada pela equipe, evitando a superposição, tão comum, quando feitas prescriçōes isoladas.

d) Plano de alta - um estudo prévio das necessidades do paciente para serem atendidas no domicíllo ou, até mesmo, no setor de Saúde Comunitária, é feito por cada elemento da equipe. Dos resultados de reuniōes de equipe surgem as orientações que são dirigidas ao paciente e familia.

e) Sessões de estudo - uma das grandes preocupações de todos os membros da equipe é a necessidade de contínuos estudos a fim de atender às constantes solicitações do método. No mínimo cada mês, a equipe apresenta ao corpo de saúde, em sessões de estudos, os resutados obtidos em situaçōes de nacientes com enfoques especiais raros ou não, ou resultados do emprego de novas técnicas, etc.

\section{3 - PARTICIPAÇAO DO ENFERMEIRO NA EQUIPE MULTIPROFISSIONAL}

Até bem recentemente o enfermeiro como membro da equipe multiprofissional, funcionou como elemento de adaptação, colaboração, coordenação e reintegração 12 . Nós o enfocamos neste trabalho, como participante desta equipe, ¿ nivel de decisão técnica, e, que pelas complexas funçōes necessita situar-se no contexto de suas atribuiçōes de caráter privativo.

O enfermeiro é o elemento da equipe de saúde mais apropriado a assumir a

* Histórico de Enfermagem para efeito deste trabalho fica entendido como levantamento e interpretaçāo de dados do paciente, familia e comunidade, visando a obtençāo de elemertos suficiente à classificaçāo diagnóstica de enfermagem; Diagnóstico de Enfermaegm fica entendico como a classifiração do nível de dependência do paciente para com os cuidados de enfermagem, referidos os problemas levantados no hístórico. 
COSTA, M.J.C. - Atuação do enfermeiro na equipe multiprofissional. Rev. Bras. Enf.; DF, $31: 321-33 S, 1978$.

coordenação do planejamento dos cuidados do paciente, conjugando as diversas prescriçōes no plano integrado e assistencial.

\section{1 - Atuação do enfermeiro a nível de decisão}

No campo da assistência à saúde, a decisão dos enfermeiros, tem sido pouco explorada e, pelas características de autonomia no campo profissional e competência técnica, propicia um novo conceito de enfermagem, e conseqüentemente maior desenvolvimento profissional.

A enfermagem moderna, como profissão cientificamente orientada, deve estar integrada aos padrōes normativos técnico-científico e ético-cultural do desempenho do papel profissional. Ela deve ser autoridade no seu campo específico, dentro dos padrōes profissionais, o que quer dizer, apenas, que em assuntos de enfermagem, é o enfermeiro aquele que decide 6 .

Para eficiente atuação do enfermeiro a nível de decisão técnico-científica e ético-profissional, torna-se necessário o contínuo estudo e revisão do processo de enfermagem pelos Enfermeiros, a fim de elevar progressivamente a qualidade de prestação de cuidados e medidas que visam atender às necessidades básicas do ser humano.

As necessidades básicas não satisfeitas dos pacientes podem significar o reflexo da omissão de cuidados de enfermagem, em contrapartida quando as necessidades afetadas dos pacientes são satisfeitas, estes aceitam melhor a terapêutica ${ }^{10}$, e então se atinge, pelo menos, o nível regular de qualidade de oferta de assistência à saúde, esta entendida como bem-estar.

O enfermeiro só assumirá mais plenamente sua responsabilidade legal perante o ser humano e comunidade sob seus cuidados, quando reconhecer que siste- maticamente deve revisar e atualizar a metodologia do processo de Enfermagem, definindo desse modo um determinado estilo de assistência.

As instituiçōes de Saúde, estão procurando se organizar, incluindo em suas normas as atribuiçōes específicas do enfermeiro, enfatizando a decisão. Assim é que a ODS n.o SAM 03.947 do INPS - contém o seguinte: "o histórico cie Enfermagem, o plano assistencial e de cuidados serão elaborados pelo enfermeiro, o qual decidirá sobre os cuidados que lhe competirá, e distribuirá os demais, pelos componentes da equipe de enfermagem, conforme suas qualificaçōes" 9.

Na publicação dos Padrōes de Atribuiçōes do Pessoal de Enfermagem, elaborado pelo Departamento de Recursos Humanos para a Saúde, do Ministério da Saúde, encontramos como primeira atribuição do enfermeiro: "Diagnosticar as necessidades de enfermagem e elaborar o plano de assistência a ser prestada pela equipe de enfermagem em serviços de proteção, de recuperação e de reabilitação da saúde" 11 .

A obrigatoriedade está prevista em estudos e Anteprojeto de Lei do Exercicio Profissional o qual expressa entre as atividades de enfermagem, aquelas de caráter privativo do enfermeiro:

a) consulta de enfermagem referente às medidas preventivas;

b) diagnóstico de Enfermagem;

c) elaboração, prescrição, subscrição no prontuário do paciente do plano de assistência de enfermagem e respectiva evolução. O referido anteprojeto, prevê airda a atividade liberal para o enfermeiro.

"O estudo do Processo de Enfermagem reflete a preocupação do enfermeiro em se iniciar na utilização de uma abordagem mais personalizada para o paciente, centrando seu trabalho nas necessidades humanas básicas: isto reafirma 
COSTA, M.J.C. - Atuaçāo do enfermeiro na equipe multiprofissional. Rev. Bras. Enf.; DF, $31: 321-33 S ;, 1978$.

um ponto de vista que comprova um ciesenvolvimento da enfermagem como ciência, cujas ações se dirigem para 0 paciente, não mais a partir de entidades clínicas e ou procedimentos técnicos, normas e ou rotinas, mas prevê uma assistência de enfermagem, a partir dos problemas identificados no paciente, este entendido na sua extensão para com a família e a comunidade e, de modo coerente com a definição de Processo de Enfermagem, como uma série de ações sistemáticas e progressivas que visam a assistência de enfermagem ao indivíduo, família e comunidade" 13 .

Pelo exposto, observa-se que para dinamizar a decisão, como forma de participação do enfermeiro na equipe multiprofissional, torna-se inevitável atentar para a definição de uma metodologia apropriada à valorização e reconhecimento do próprio processo de assistir em enfermagem.

\section{$3.1 .1 \div$ O processo de enfermagem co- mo roteiro para atuação do en- fermeiro na equipe multipro- fissional}

Para um eficiente desempenho do enfermeiro na equipe multiprofissional é necessário o reconhecimento das etapas do processo de enfermagem como ações progressivas interrelacionadas e sinérgicas, funcionando como reiteração de um ordenamento lógico como segue:

- Histórico e Diagnóstico de Enfermagem

- Plano Assistencial de Enfermagem

- Plano de Cuidados de Enfermagem

- Evolução de Enfermagem

- Prognóstico de Enfermagem.

Passaremos à descrição e análise sucinta das etapas do Processo de Enferjnagem como um roteiro necessário ao desenvolvimento do trabalho do enfermeiro na equipe multiprofissional, em uma unidade de internação. Algumas alterações foram introduzidas para tornar funcional a aplicação do método.

\section{- HISTÓRICO DE ENFERMAGEM}

Apresentamos um modelo ANEXO I, ie forma resumida para evitar perda de tempo do profissional e do paciente frente a um longo histórico e, sobretudo poupar o gasto do energia do resultante de uma entrevista demorada.

Sendo o diagnóstico de enfermagem o resultado do histórico (após identificar as situaçõas do paciente, analisá-las e extrair aquelas que representam problemas de enfermagem), achamos mais adequado fazê-lo constar no final da folha do histórico. Dessa forma, ficam centralizadas num só impresso as duas primeiras etapas do processo de enfermagem:

a) Finalidade - o histórico de Enfermagem tem por finalidade, registrar cados que permitam a identificação e análise das situações do paciente que venham constituir problemas de enfermagem a fim de, identificar as necess:idades afetadas, dependência de enfermagem, enfim, determinar o diagnóstico de enfermagem.

b) Descrição - Histórico de Enfermagem - destina-se ao registro dos resultados da entrevista com o paciente, baseados em observações do comportamento interpessoal enfermeiro-paciente, formulando perguntas somente relacionadas aos itens subjetivos de acordo com o roteiro, antes anotando os números correspondentes.

- Problemas identificados - anotar nesta coluna os problemas encontrados, relacionando-os com as necessidades humanas básicas.

- Necessidades afetadas - registrar a necessidade afetada, prioritariamente :elacionada a cada problema.

- Dependência de Enfermagem znarcar com um $\mathrm{X}$ no quadro correspon- 
COSTA, M.J.C. - Atuaçāo do enfermeiro na equipe multiprofissional. Rev. Bras. Enf.; DF, $31: 321-339,1978$.

dente à dependência do paciente em natureza, de acordo com a necessidade afetada.

- Diagnóstico - registrar o sumário de todas as dependências que o paciente tem do enfermeiro em termos das necessidades humanas afetadas, total e parcial.

- Extensão - numerar pela ordem de 1 a 4 a extensão da dependência de acordo com o grau de cada necessidade.

\subsubsection{2 - Plano Assistencial de Enfermagem}

E aconselhável constar no mesmo impresso as frases que se relacionam, pois além de permitir uma visão geral do que vai ocorrendo com o paciente, utiliza o máximo de espaço evitando avolumar o prontuário do paciente com a inclusão de mais impressos. Neste modelo ANEXO 2, estão constando: Plano Assistencial de Enfermagem, Prognóstico e Alta.

a) Finalidade do Plano Assistencial de Enfermagem - permitir traçar em linhas gerais a previsão de toda a assistência que o paciente deve receber enquanto estiver dependente da enfermagem durante a hospitalização e, estimar a probabilidade do mesmo tornar-se independente no auto-cuidar-se.

b) Descrição - classificação da dependência - anotar as siglas da dependência de enfermagem de acordo com a necessidade afetada, observando $o$ diagnóstico de enfermagem.

- Assistência de Enfermagem - reEistrar as necessidades relacionadas com os problemas manifestados pelos pacientes, que necessitam a intervenção de enfermagem para ajudar a solucioná-los.

- Aprazamento - anotar a freqüência diária, semanal, quinzenal, mensal, etc., dos cuidados a serem prestados ao paciente.

- Prognóstico - local destinado a anotar a probabilidade do paciente al- cançar sua independência da enfermagem.

- Alta - marcar com um X no local correspondente à alta: curada, quando o paciente está capaz de auto-cuidarse. Para outro profissional, quando o problema encontrado depende da ajuda de outro profissional para atender às necessidades que não foram totalmente sanadas no período de hospitalização. Para saúde comunitária, quando o paciente deixa o hospital, ainda necessitado da assistência de enfermagem no domicílio ou ambulatório.

\subsubsection{3 - Evolução Clínica}

A utilização da folha única de Evolução Clínica ANEXO 3, permite anotaçõss integradas, facilitando a comunicação entre os elementos da equipe e uma rápida visualização do estado geral do paciente. Isto permite aos elementos da equipe tomarem conhecimento dos registros de interesse multiprofissional os quais servem de apoio às prescriçōes.

a) Finalidade da Evolução Clínica destina-se ao relatório específico, sobre o estado evolutivo do paciente, mudanças de diagnóstico, condiçōes ao ser dada alta, instruçōes, etc.

\subsubsection{4 - Prescrição}

Como na Evolução" Clínica, a prescrição efetuada em folha única, ANEXO 4, permite a integração da assistência, visto que o tratamento determinado por um profissional sempre se relaciona com outro, principalmente quando o trabatho é desenvolvido em equipe.

a) Finalidade da prescrição - perm!te aos profissionais prescreverem tratamentos para seus pacientes e mantê-los em observação, (através dos registros, de queixas e reações nas 24 horas).

b) Descrição:

- Prescrições - espaço destinado aos pæofissionais para prescriçāo da medi- 
COSTA, M.J.C. - Atuaçāo do enfermeiro na equipe multiprofissional. Rev. Bras. Enf.; DF, $31: 321-339,1978$.

cação, dieta, tratamento, sendo que as prescrições de enfermagem serão relacionadas com o atendimento das necessidades básicas humanas, e visam preponderantemente o bem-estar dos pacientes.

- Horário - coluna para manter em registro medicamentos e tratamentos prescritos e executados nos três turnos, bem como o controle global das prescrições.

- Observações - no momento de início ou abertura de cada prontuário, serão anotados, de forma sucinta, dados relativos 'à admissão, e, posteriormente, o resumo das queixas e sintomatologia, etc., apresentadas pelo paciente.

\subsubsection{5 - Plano de Cuidados de Enfermagem}

A continuidade e coordenação da Assistência de Enfermagem prestada ao paciente pela equipe de enfermagem, deve ser rigorosamente controlada. Este modelo ANEXO 5 (sugerida a impressão tipo Kardex), é utilizida como um guia para administração de medicamentos e tratamentos. Atendidos todos os itens relacionados com as prescrições, após 24 horas, anexar ao prontuário como documento de alto valor. $O$ preenchimento portanto é feito a tinta, evitando rasuras.

No anverso, as faixas coloridas separam os medicamentos de acordo com a via de administração ou finalidade, para manter uma rápida visão do conteúdo bem como manter a tradição sobre os cartões de distribuição de medicamentos, tão bem utilizados anteriormente, os quais eram impressos em cores.

a) Finalidade do plano de cuidados de Enfermagem - transcrever a prescrição dos profissionais permitindo racionalização do trabalho para o serviço de enfermagem e manter o controle de freqüência do atendimento nos três turnos. b) Descrição (anverso) :

- Discriminação - transcrever a prescrição do médico como sugere a coluna contendo as vias de administração dos medicamentos.

- Via - anotar a via de administração de acordo com a prescrição.

- Turnos - anotar o horário de cada turno em que a medicação é administrada observando a $1 .^{\text {a }}$ coluna que separa os tipos de medicamentos.

c) Descrição (verso):

- Discriminação - transcrever a jorescrição do enfermeiro e outros profissionais, como sugere a coluna destinada a tratamentos.

- Controles - espaço para transcrição dos controles como por exemplo: P.A., TPR, peso, altura, glicosúria, líquidos ingeridos e eliminados, jejum, repouso, posições, tipo de movimentação e deambulação, encaminhamentos para R.X., fisioterapia, odontologia, remoțão de sutura, dreno, tampões, sonda, curativo, exercícios físicos e respiratórios, lavagens, instilações, etc.

- Higiene - transcrever o tipo de higiene que o paciente vai receber. Ex.: banho, higiene oral, de cabeça, das unhas, cavidades, tricotomia, etc.

- Integração - transcrever as recomendações quanto à assistência psicosucial e espiritual do paciente. Ex.: Psico-social: orientação com relação ao ambiente hospitalar, os aspectos sociais da doença que está acometido, o tipo de tratamento ou cuidados que vai receber, abordagem recomendável, ocupação indicada no período de hospitalizacão, recreação, visitas, entrevistas, etc.

- Integração espiritual - fundamentada em valores religiosos e/ou filosofia de vida. Ex.: dia e hora em que pode receber a comunhão, apreciação conjunta sobre um filme, artigo, ou programa, que explore um tema de vida, etc. 
COSTA, M.J.C. - Atuação do enfermeiro na equipe multiprofissional. Rev. Bras. Enf.; DF, $31: 321-335,1978$.

\subsubsection{6 - Guia de Encaminhamento de Enfermagem}

No exercício da profissão, o enfermeiro identifica problemas no paciente que transcendem às suas atribuições, derendo encaminhá-lo a outros profissionais a fim de receber 0 atendimento necessário. ANEXO 6.

a) Finalidade da Guia de Encaminhamento de Enfermagem - encaminhar o paciente com problemas que exijam atendimento de outros profissionais.

b) Descrição:

- Ao serviço - anotar o nome do serviço onde o paciente vai ser atendido.

- Motivo do encaminhamento - especificar os principais sintomas do paciente e os dados sobre os quais julga necessário o atendimento.

Razões como essa ressaltam um fator nuito importante a ser observado quando se trabalha com o Processo de Enfermagem, qual seja a fixação do número de pacientes por enfermeiro.

O trabalho em equipe multiprofissional torna-se inviável quando é atribuíro a apenas um dos elementos a maior parte dos encargos assistenciais, como vem ocorrendo rotineiramente com 0 enfermeiro.

Os estudos existentes para a determinação do número de pacientes por enfermeiro, não coincidem com a moderra assistência de enfermagem. É sabido que o número de pacientes por enfermeiro vai depender principalmente $d$ J nível de dependência que os primeircs e.presentarem com relação à enfermagem. A experiência tem indicado de um modo geral, que ao fazer uma abordagem científica no Processo de Enfermagem, resulta demanda de tempo muito superior ao simples atendimento tradicional. Observadas detalhadamente todas as etapas do Processo de Enfermagem, importa em 40 minutos o tem- po empregado para a sistemática diária de cada paciente. Considerando-se 8 horas de trabalho diário, resulta 12 pacientes por enfermeiro. certo que o enfermeiro da unidade não vai realizar efetivamente por si só todos os passos do Processo de Enfermagem, pois há atividades delegáveis dentro da etapa denominada plano de cuidados. No entanto, há de considerar-se que o enfermeiro numa unidade de internação necessita de horas para:

- determinar as necessidades dos pacientes, inclusive executar parte desses cuidados;

- ministrar a edućação em serviço, a nível de clínica;

- desempenhar a gerência da unidade de Enfermagem relacionada con a limpeza, suprimentos e estoques;

- desenvolver atividades de comunicação, informação e intercâmbio com a administração, correlatos, dirigidos e com a família do paciente 4 .

E ainda,

- desenvolver atividades educativas a grupos de familiares e comunidades iigadas aos pacientes.

\section{4 - CONCLUSAO}

- O trabalho em Equipe Multiprofissional é uma necessidade, visto pernitir aos profissionais, maior satisfação pelo elevado níver de assistência ao paciente com ampla margem de segurança.

- Apesar do atual número de enfermeiros não atender às necessidades exigidas pelo paciente, é necessário que os existentes conscientizem-se do papel a desempenhar na equioe multiprofissional, principalmente a nível decisório.

- Podemos considerar que estamos nc limiar de uma nova fase de desenvolvimento para a enfermagem com a perspectiva de, em breve, poder utilizar sistematicamente uma metodologia científica no Processo de Enfermagem. 
COSTA, M.J.C. - Atuaçāo do enfermeiro na equipe multiprofissional. Rev. Bras. Enf.; DF, 31 : 321-33S, 1978.

- O exercício da profissão de enfermeiro exige execução de funçōes privativas do enfermeiro, indelegáveis, sobre as quais só os profissionais podem opinar, afirmando o reconhecimento científico.

\section{REFERENCIAS BIBLIOGRAFICAS}

1. ALVARENGA, Adelaide - A necessidade de Equipe Multiprofissional para melhor atendimento hospitalar. Rev. Paulista de Hospitais, Sāo Paulo, 21 (1) :36-8, janeiro, 1973.

2. BRASIL, Ministério da Educação e Cultura/DAU - Estudo sobre a formaçāo e utilizaçāo dos recursos rumanos na Area de Saúde, Brasília, 1976.

3. CIANCIARULIO, Tamara Iwanow - $\mathrm{O}$ histórico' de Enfermagem no contexto do Processo de Enfermagem - Parte II. Enf. em Novas Dimens. Sāo Paulo, 2 (4) :127-89, 1976.

4. DOURADO - Haydée G. \& Costa, Ivaneyde D. - A Equipe de Enfermagem. Rev. Brasileira de Enfermagem, Rio de Janeiro, 27 (1) :82-5, janeiro/março, 1974.

5. FELICE, Sebastiāo André de - Equipe Multiprofissional - Conceito e funçōes. Rev. Paulista de Hospitais, São Paulo, 14 (8):370-74, agosto, 1976.

6. FERREIRA SANTOS, Célia A. - A Enfermagem como profissão. Săo Paulo, Pioneira, 1973.

7. HORTA, Wanda de Aguiar - O histórico de Enfermagem simplificado,
Enf. em Novas Dimens., São Paulo, 2 (3) :131-38, 1976.

8. INPS - ODS N. ${ }^{\circ}-\mathrm{SAM}-399.16-$ Aprova modelos de impressos para uso dos Servidores de Assistência Médica. BS/INPS 145. 03 de agosto de 1970.

9. INPS - ODS N..$^{\circ}$ - SAM - $039.47-$ Dispōe sobre a prestação da assistência de enfermagem nas Unidades Médico-Asistencials, 20 de julho de 1977.

10. KOIZUMI, M. S. \& CIAUCIARULIO T. I. - Assistência de Enfermagem e cuidados de Enfermagem. Enf. em Novas Dimens., São Paulo, 4 (1): 40-3, 1978.

11. Matos, A. V. et al - Padrōes de atribuiçōes do Pessoal de Enfermagem, s 1, s.c.p., 1972.

12. NASCIMENTO, Zélia P. - O Enfermeiro - Membro da Equipe Multiprofissional. Rev. Paulista de Hospitais, Såo Paulo, 24 (5) :213-15, maio/1976.

13. PAIM. Iygia et al - Iniciamento $\mathbf{s}$ Metodologia do Processo de Enfermagem. Publicaçăo da ABEn, Secảo Rio de Janeiro, Rio de Janeiro, 1973. 


\section{A NEXO-1}

\section{HISTÓRICO DE ENFERMAGEM}

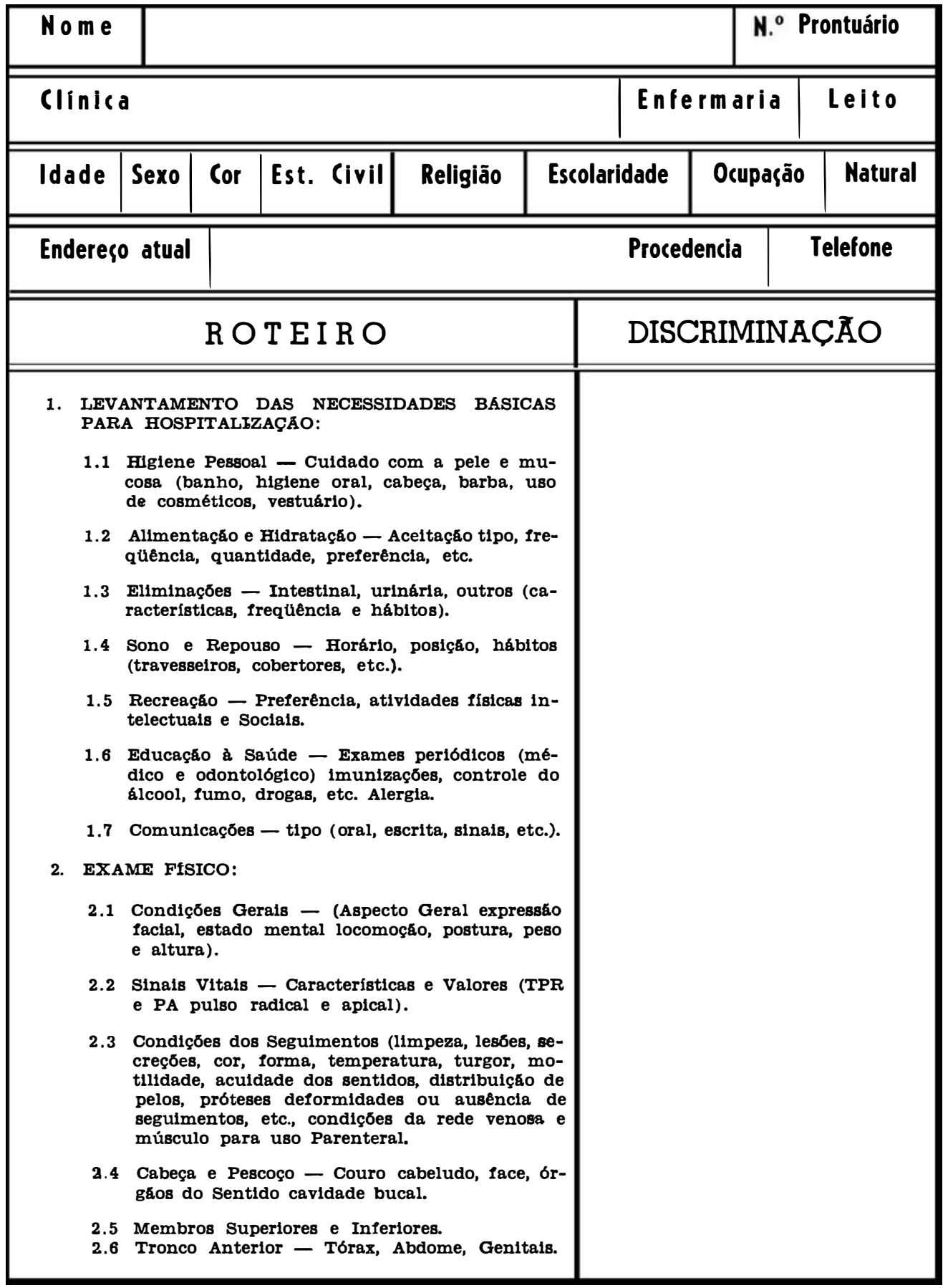


2.7 Tronco Posterlor - Toráx, lombo, Sacra, nádegas, reg. anal.

3. PERCEPÇOES E EXPECTATIVAS:

3.1 Necessidades Sentidas - o que incomoda, preocupaçóes, queixas, problemas, medo. $O$ que sabe sobre a doença e tratamentos. Experiênclas anteriores. O que espera da Institulçáo e da Equipe de Saúde.

3.2 Impressరes do Enfermelro sobre o aspecto: reservado, tímldo, ansioso, revoltado, etc.

4. DAdOS Clf́NICOS DE INTERESSE PARA ENFERMAGEM:

4.1 Resultados de exames (Gerals e Específicos ao Diagnóstico Médico).

4.2 Dlagnóstico e prescriçăo Médica.

5. CONCLUSOES:

Problemas Identificados Nec. afetadas

Depend. de Enfermagem

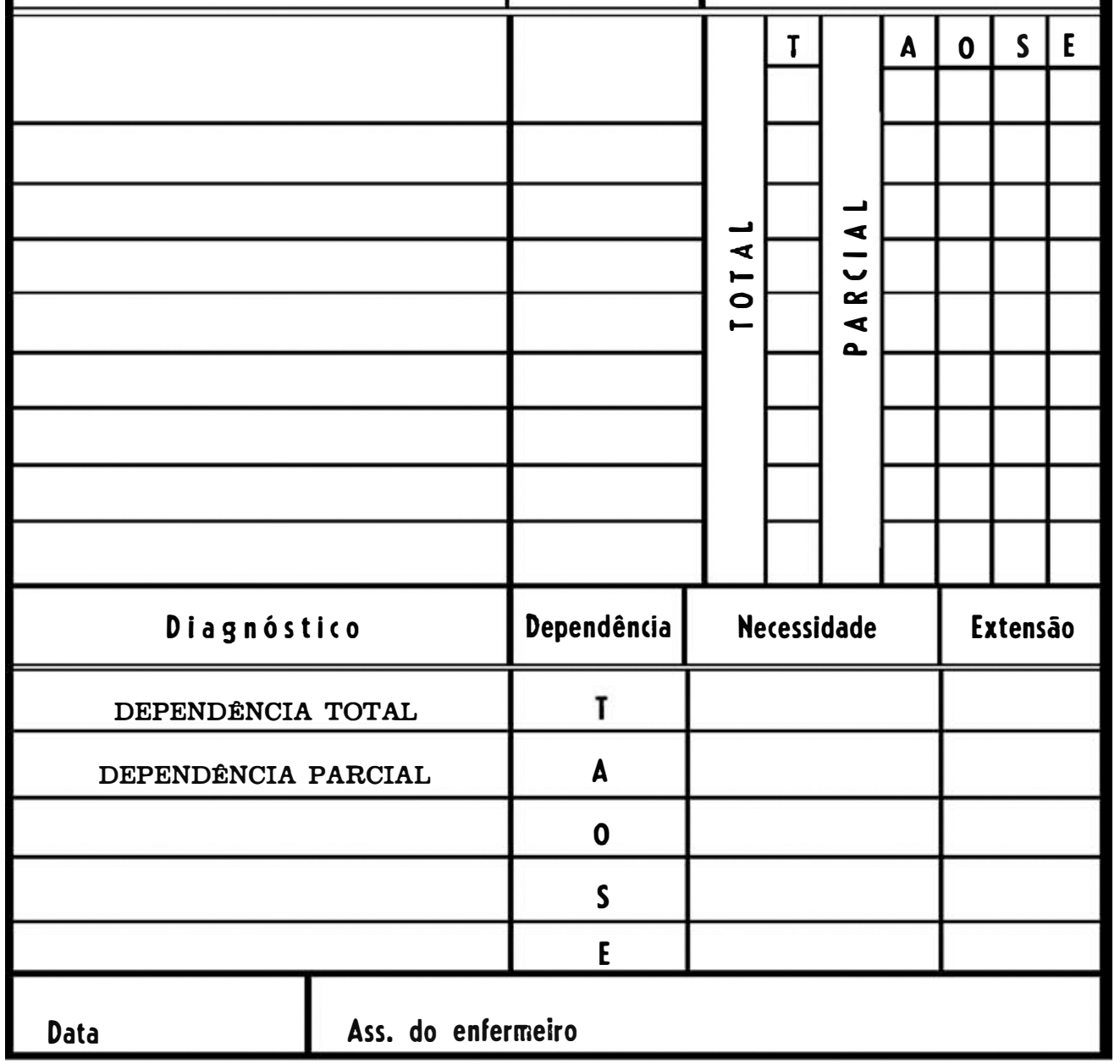


ANEXO 2

PLANO ASSISTENCIAL DE ENFERMAGEM

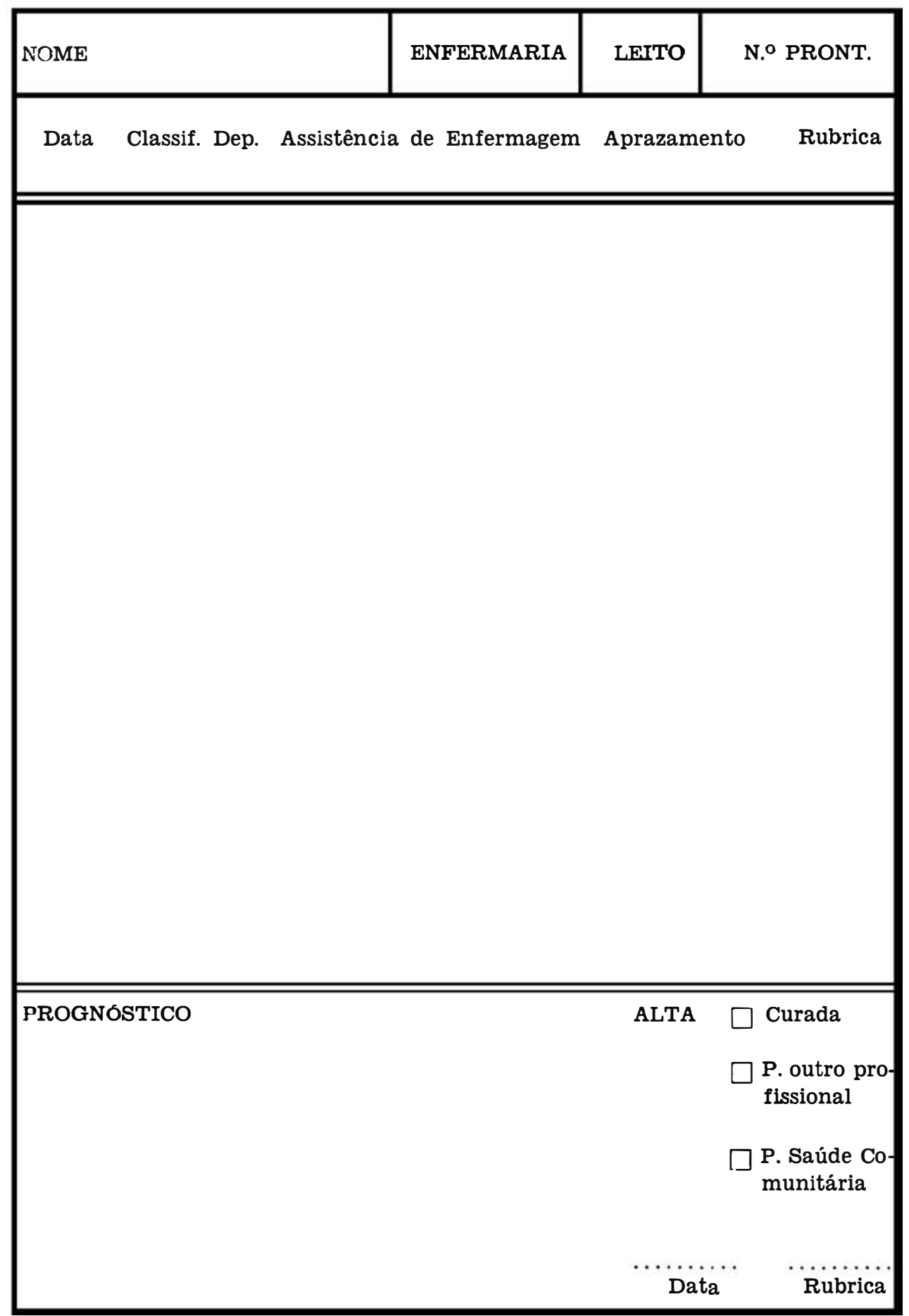


COSTA, M.J.C. - Atuaçāo do enfermeiro na equipe multiprofissional. Rev. Bras. Enf.; DF, $31: 321-335,1978$.

ANEXO 3

EVOLUÇAO CLINICA

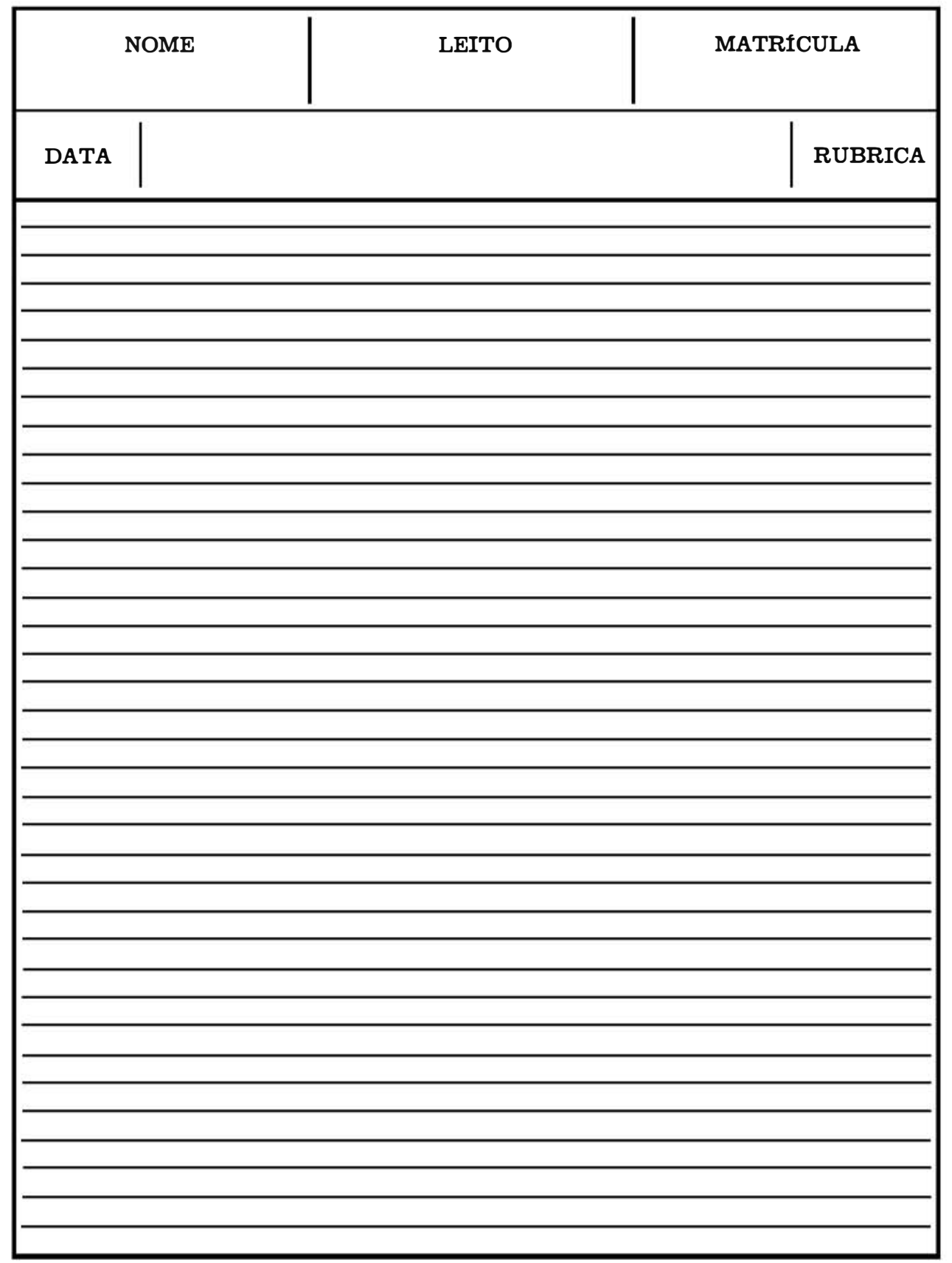


COSTA, M.J.C. - Atuaçāo do enfermeiro na equipe multiprofissional. Rev. Bras. Enf.; DF, 31 : 321-33S, 1978.

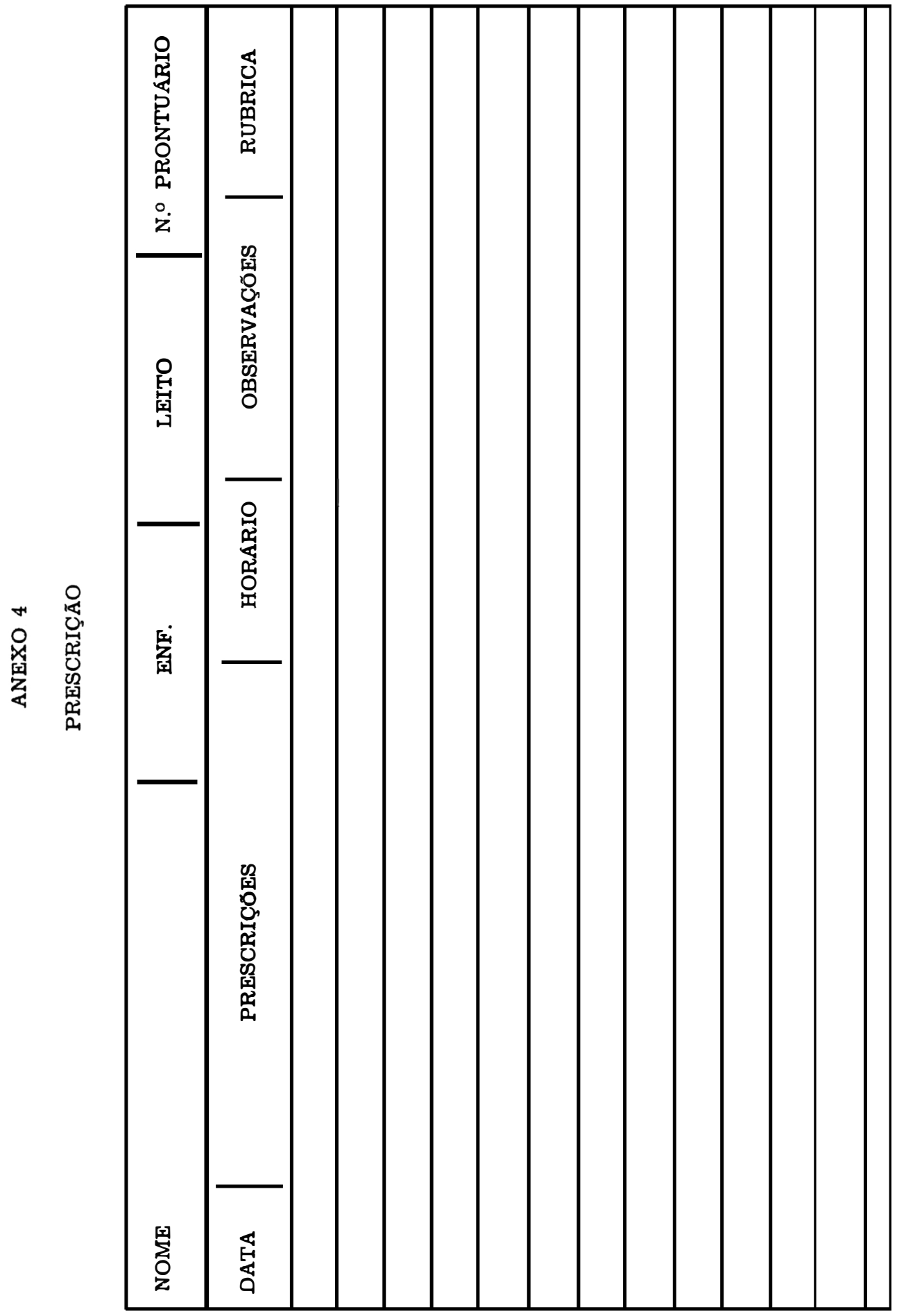


COSTA, M.J.C. - Atuação do enfermeiro na equipe multiprofissional. Rev. Bras. Enf.; DF, 31 : 321-339, 1978.

\section{ANEXO 5}

PLANO DE CUIDADOS DE ENFERMAGEM

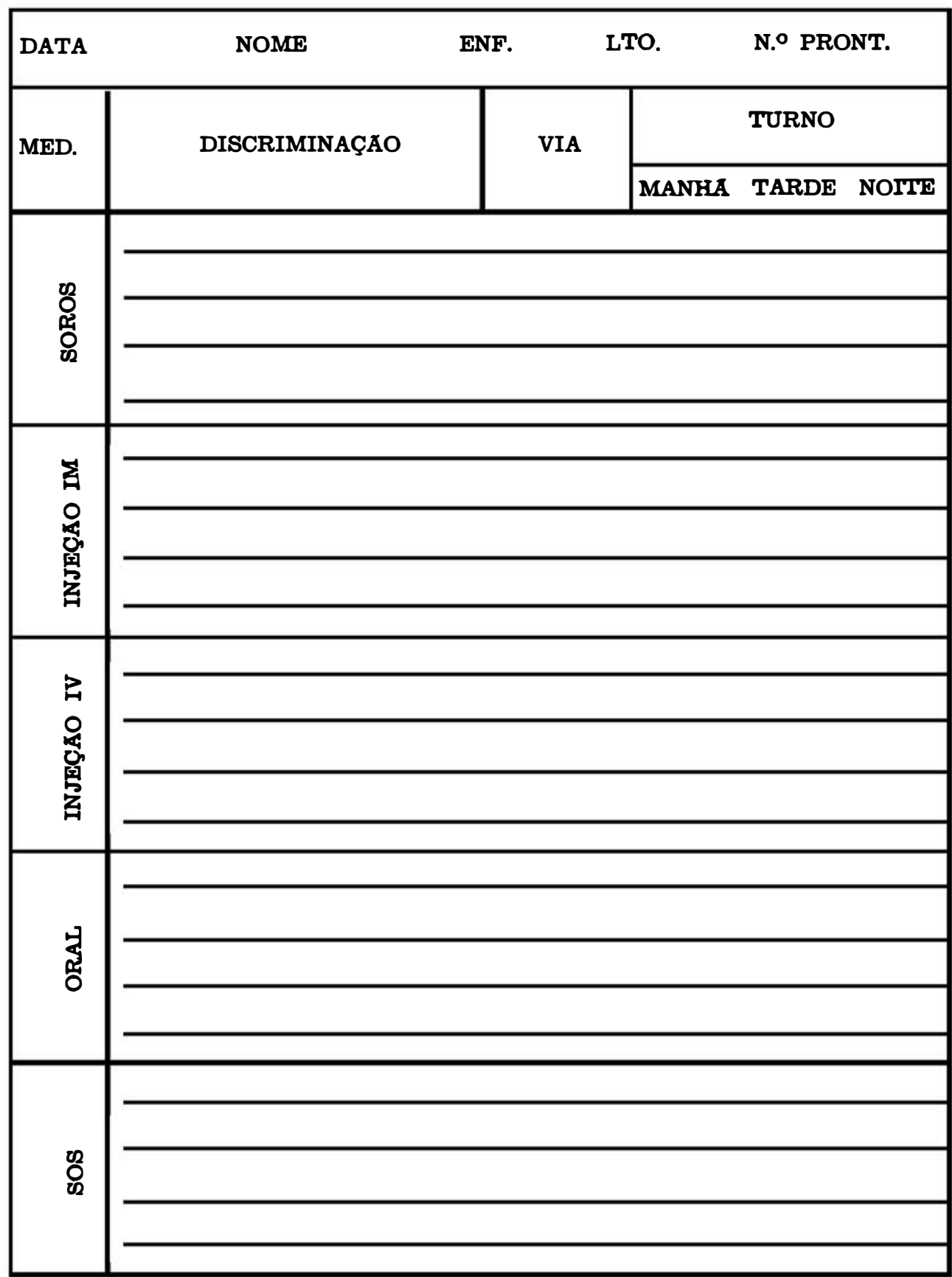


COSTA, M.J.C. - Atuaçāo do enfermeiro na equipe multiprofissional. Rev. Bras. Enf.; DF, 31 : 321-339, 1978.

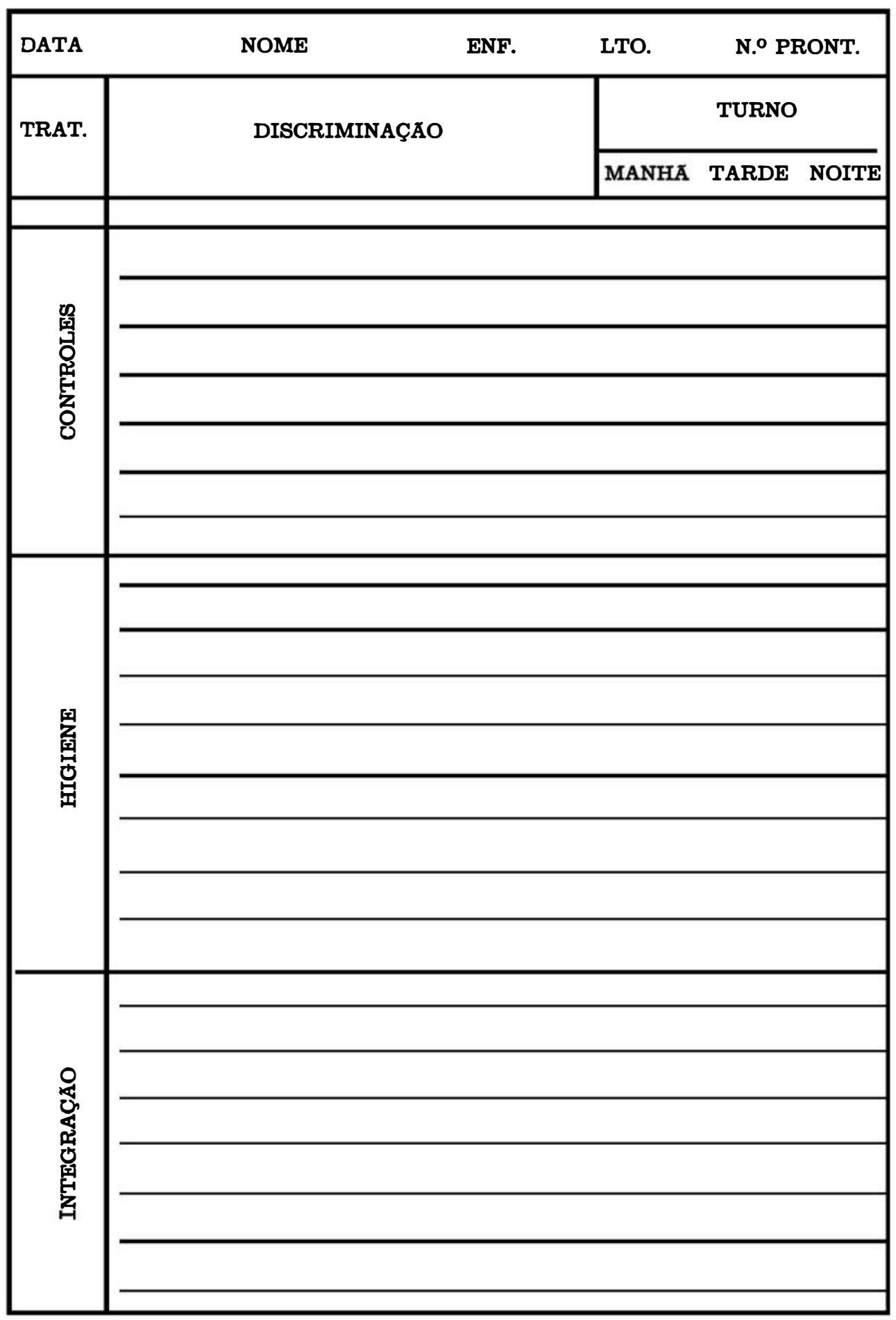


COSTA, M.J.C. - Atuaçāo do enfermeiro na equipe multiprofissional. Rev. Bras. Ene.; DF, $31: 321-33 S, 1978$.

ANEXO 6

GUIA DE ENCAMINHAMENTO DE ENFERMAGEM

\begin{tabular}{|c|c|c|c|c|}
\hline NOME & & ENF. & LTO. & N.c PRONT \\
\hline \multicolumn{5}{|c|}{ AO SERVIÇO DE: } \\
\hline \multicolumn{5}{|c|}{ MOTIVO DO ENCAMINHAMENTO } \\
\hline DATA: & I & ENFER & $0: \ldots$ & \\
\hline
\end{tabular}

